\title{
Factors Affecting the Organizational Adoption of Blockchain Technology: An Australian Perspective
}

\author{
Saleem Malik \\ Federation University Australia \\ smalik@,federation.edu.au
}

\author{
Mehmood Chadhar \\ Federation University Australia \\ m.chadhar@federation.edu.au
}

\author{
Madhu Chetty \\ Federation University Australia \\ madhu.chetty@,federation.edu.au
}

\begin{abstract}
Blockchain Technology (BCT) is a novel innovation that has the potential to transform industries, for instance, supply chain, energy, finance, and healthcare. However, despite the potential and the wide range of benefits reported, organizational adoption of BCT is low in several countries including Australia. Some studies investigated the adoption of BCT in different countries, however, there is a lack of research that examines the organizational adoption of $B C T$ in Australia. This study fills this gap by exploring the factors, which influence BCT adoption among Australian organizations. To achieve this, we used an interpretative qualitative research approach based on the Technology, Organization, and Environment (TOE) framework and the Institutional Theory. The findings show that organizational adoption of BCT in Australia is influenced by perceived novelty, complexity, cost, and disintermediation feature of BCT; top management knowledge and support; government support, customer pressure, trading partner readiness, and consensus among trading partners.
\end{abstract}

\section{Introduction}

Blockchain Technology (BCT) is a digital ledger that manages data over a distributed, decentralized, and peer-peer network through smart contracts without the need of any intermediary [1]. Every node over the BCT network has the same copy of data, and any change in the data is made through a mutual consensus among the nodes. The transactions over the BCT network are timestamped, immutable, and back traceable. Therefore, BCT offers better transparency, fraud detection, improved security, data provenance, and authenticity in businesses. Initially, the BCT was designed for cryptocurrencies like Bitcoin. However, recently multiple uses of BCT are proposed in finance, healthcare, supply chains, energy, and many other sectors [2]. BCT has significantly contributed to the global trade volume $[3,4]$. For many years, BCT has been in Google's top trends. Gartner, Forbes, the Economist, and Fortune also reported BCT among its top megatrends. Big companies like IBM, Walmart, and Microsoft explored possible uses of BCT for their businesses [3,5]. Despite all this, the review of scholarly and commercial literature reveals that BCT has not reached its heavy adoption among organizations all over the globe [6-10]. This lack of uptake of BCT by organizations necessitates us to investigate the rationale for its low adoption among Australian organizations. The following section provides a review of the studies that tried to investigate the adoption of BCT.

\subsection{Studies on Blockchain adoption}

Streng [11], Duy et al. [12], Parino et al. [13], and Batubara et al. [14] proposed BCT use cases for organizations and governments. Kokina et al. [15] presented an overview of the $\mathrm{BCT}$ practices adopted by different accounting firms. A similar study was conducted by Taufiq et al. [16]. Wang et al. [17] proposed a maturity model. However, their model was not derived from empirical evidence. Kamble et al. [18] investigated factors influencing individuals to adopt BCT in the supply chain industry. Supranee and Rotchanakitumnuai [19] conducted a similar study in the Thai automotive industry. Another study in the supply chain was conducted by Kshetri and Loukoianova [20]. Holotiuk and Moormann [21] investigated the factors influencing BCT adoption in the finance industry of Germany. They developed a general framework and ignored the BCT-specific factors. Wong et al. [6] conducted a similar study for Malaysian SMEs in the supply chain business. Kulkarni and Patil [22], Koster and Borgman [23], and Kühn, et al. [24] investigated the adoption of BCT in India, Netherland, and Germany respectively. Clohessy and Acton [25] explored the impact of top management support, organization size, and organizational readiness on the adoption of BCT in Ireland. They studied the impact of few selective factors only. Albrecht et al. [26] investigated the 
implementation of BCT in the energy sector. They studied the implementation stage of the adoption process of BCT. Werner et al. [27] investigated the potential influence of BCT adoption on a company's competitive performance.

From the above review, it is apparent that there is a lack of study that explores the organizational adoption of BCT in Australia. Therefore, we aim to find the answer of:

"What factors are influencing the adoption of blockchain technology (BCT) among Australian organizations?"

The rest of the paper is as follows: Section 2 provides an overview of the BCT in Australia. Section 3 explains the theoretical foundations of the study. Section 4 describes the methodology part of the paper and elaborates on the information related to the sample selection, sample size, data collection, and interview process. Section 5 elucidates the interview data analysis and findings. Section 6 is devoted to the discussions and contributions of the study. Section 7 concludes the paper, explains limitations, and the directions for future research.

\section{Blockchain in Australia}

Australia considers the emergence of new and exciting technologies like BCT as far-reaching opportunities. The Australian government started working with BCT in 2016 when Standards Australia submitted a New Field of Technical Activity (NFTA) proposal on behalf of the Australian government to the International Organization for Standardization (ISO) to develop standards to support BCT [28]. Since then, the Australian government has put significant efforts to promote BCT. Following are the recent BCT projects of the Australian government:

- The Australian government has issued a roadmap for BCT, which states that "the Australian government has provided support and funding for the government, private sector, and researchers, to foster innovation and collaboration around BCT, through programs such as Austrade business missions to international markets; the Entrepreneur's Program; Australian Research Council Grants; and Business Research and Innovation Initiative pilots" [29].

- Another recent project of the Australian government is the trading of water rights using BCT [30].

- One of its research agencies, CSIRO's Data61, has been working to develop a national blockchain through which the Australian government has plans to integrate its different departments for better coordination and data sharing among them $[31,32]$.

- The Australian Stock Exchange (ASX) and the Australian National Bank (NAB) have been exploring $\mathrm{BCT}$ to find its possible uses for their business operations [33].

- The Australian government has a partnership with IBM to accelerate the uptake of BCT [34].

There is also a great support for BCT at the private level in Australia. Blockchain Australia, formerly known as the Australian Digital Commerce Association (ADCA), has actively been promoting the adoption of BCT among Australian organizations [35]. According to a report from Deloitte [36], Australia has the potential to become a global BCT leader. The Economist Intelligence Unit (EIU), a world reliable organization, ranked Australia to be the first in its technology readiness index [37], indicating that Australia has all the required infrastructure to embrace new technology like BCT. Despite having supports from the government and private sector, BCT has not been adopted by Australian organizations heavily [36, 38].

\section{Theoretical Preliminaries}

Technology adoption occurs at both individual and organizational levels and there are a large number of studies in this regard [43]. Researchers have developed and used several theories and models at both levels separately. This study focuses on BCT adoption and relevant theories at the organizational level.

Oliveira and Martins [39] reviewed the literature and reported that the majority of the studies on IT adoption at the organizational level use the Diffusion of Innovation (DoI) theory [40] and the Technology, Environment, and Environment (TOE) framework [41].

The DoI theory states that the organization's decision to adopt new technology is influenced by the characteristics of the technology and the organization per se that is going to adopt that technology. The TOE framework describes that the organization's decision to adopt new technology is not only influenced by the technology and organization, but it is also affected by the environment in which the organization runs its business. Thus, the TOE framework complements the DoI theory by adding the environment context and provides a better solid theoretical basis for the investigation of an IT adoption. Therefore, the authors of this study selected the TOE framework as a theoretical lens to explore BCT adoption. The TOE framework has widely been used to study the adoption of various technologies such as ERP systems, FRID, big data, cloud computing, website, etc. [39, 42]. However, Verma and Bhattacharyya [43] stated that the TOE 
framework alone is incapable of understanding the IT adoption of interactive and complex technologies like $\mathrm{BCT}$. This is because, the BCT is an inter-organizational technology and the decision to its adoption requires cooperation, collaboration, and interdependency among the organizations working together [27], which is not addressed by the TOE framework [26]. The TOE framework is static, in that, it overlooks the complex interactions between or among the organizations [44]. To supplement this shortcoming of the TOE framework, we integrated the Institutional Theory [45], which is known to explain the interactions among organizations, to its environmental context. Oliveira and Martins [39] reported the review of studies that integrated the TOE framework and Institutional Theory to explore the adoption of different inter-organizational technologies such as e-commerce and EDI.

The following sub-sections further explains the TOE framework and the Institutional Theory.

\subsection{TOE Framework}

The TOE framework, originally developed by Tornatsky and Fleischer [41], consists of three contexts, namely, technological, organizational, and environmental that influence the organization's decision to adopt new technology.

Technological Contexts. Technological context refers to how the characteristics of technology per se influence its adoption. Examples of technology contexts include relative advantage, complexity, compatibility, observability, trialability, cost, and risk associated with technology [42].

Organizational Contexts. Organizational context refers to the organization's characteristics and resources, which influence the adoption of new technology such as organization size, top management support, organization culture, organization readiness, and organization structure [42].

Environmental Context. Environment context refers to the environment in which an organization runs its business. This includes the external factors that create opportunities and uncertainties for organizations to adopt new technology. Competitive pressure and government support and regulations are prominent examples of the environmental context [42].

\subsection{Institutional Theory}

Institutional Theory explains how organizations influence each other while deciding the adoption of new technology. According to DiMaggio and Powell [45], the authors of the Institutional Theory, organizations can not make a purely internally driven decision in an institutionalized environment. They are likely to be dependent on each other while making any decision such as the adoption of an inter-organizational system like BCT. They further assert that coercive, normative, and mimetic pressures make organizations isomorphic.

\section{Methodology}

To find the answer of the research question, an interpretive qualitative research approach, proposed by Klein and Myers [46], was considered appropriate for this study. This approach helps to explore new issues when there is inadequate or little research available to understand it; the issue cannot be understood without the context and the meanings people assigned to it [47]. This is particularly relevant to our study because there is a lack of research that examines the organizational adoption of BCT in the Australian context. Therefore, the interpretive research approach was selected and utilized.

We conducted in-depth semi-structured interviews of the key persons from the organizations that either adopted BCT or were in the adoption process.

Selection of Organizations. To search the relevant organizations and their information e.g. contact person, industry type, adoption status of BCT, we used the following strategies: (1) search with Google and LinkedIn, (2) use of our professional network, and snowball sampling technique, (3) examination of various industry reports and organizations' press releases, and (4) scanning of the BCT related workshops and conferences. After collecting the required information, we sent an invitational email to the organizations, containing information concerning the research as well as the consent form. The organizations, willing to participate in the research, indicated their consent by returning the signed consent form and by nominating a person (informant) able to give the required information on BCT adoption. As recommended by Hill et al. [48], we sent tentative questions to the nominated informant one week before the interview which gave him ample time to get familiar and prepare for the interview. Table 1 shows the details of participating organizations and their informants.

Table 1. Organizations and their informants

\begin{tabular}{|c|c|c|c|}
\hline $\begin{array}{c}\text { Type of } \\
\text { Organization }\end{array}$ & Informant & : & 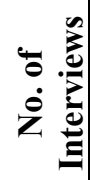 \\
\hline IT & Founder & A1 & 1 \\
\hline
\end{tabular}




\begin{tabular}{|c|l|c|c|}
\hline \multirow{5}{*}{ Finance } & $\begin{array}{l}\text { Software } \\
\text { Engineer }\end{array}$ & A2 & 1 \\
\cline { 2 - 4 } & System Analyst & A3 & 1 \\
\cline { 2 - 4 } & CTO & A4 & 1 \\
\cline { 2 - 4 } & Project Manager & A5 & 1 \\
\cline { 2 - 4 } & CEO & A6-8 & 3 \\
\hline \multirow{3}{*}{ Travel } & Co-Founder & A9 & 1 \\
\cline { 2 - 4 } & CTO & A10 & 1 \\
\cline { 2 - 4 } & CEO & A11 & 1 \\
\cline { 2 - 4 } Education & Technical Analyst & A12 & 1 \\
\hline \multirow{2}{*}{ Government } & Co-Founder & A14 & 1 \\
\hline \multirow{5}{*}{ Consulting } & $\begin{array}{l}\text { Senior Computer } \\
\text { Forensics Officer }\end{array}$ & A15 & 1 \\
\cline { 2 - 4 } & CEO & A16- & 2 \\
\cline { 2 - 4 } & Project Manager & A17 & 1 \\
\cline { 2 - 4 } & $\begin{array}{l}\text { Solution } \\
\text { Architect }\end{array}$ & A19 & 1 \\
\hline \multirow{2}{*}{ Legal } & CEO & A20- & \multirow{2}{*}{3} \\
\cline { 2 - 4 } & Director & A23 & 1 \\
\hline \multirow{2}{*}{ Total } & \multicolumn{2}{|c|}{} & $\mathbf{2 3}$ \\
\hline
\end{tabular}

Informants Selection. To gather reliable information, the informants were selected very carefully. Only those informants were selected that fulfilled the following criteria:

- They should able to demonstrate extensive knowledge/expertise in BCT.

- They should involved with the actions/decisions of the organization to adopt BCT.

Sample Method. We used theoretical sampling for the data collection. We selected organizations and informants that fit with the purpose of our study.

Data Collection and Interview Process. The primary data was collected through the semi-structured interviews that were carried out until the data saturation was achieved as suggested by Glaser and Strauss [49]. It took seven months (June 2019-December 2019) to conduct the interviews. We conducted 23 interviews. The semi-structured interviews provide the flexibility to cover all the information related to the phenomena under investigation [50]. Out of 23 interviews, 20 were conducted over Skype, and for the remaining three, we visited the organization's premises. Every interview lasted for 30-60 minutes. An interview guide was developed to ask relevant and specific questions. An expert opinion was sought from the senior academics and researchers to remove flaws within the interview guide. Every interview was transcribed and analyzed after its completion. The interview guide was updated according to the findings of every interview. Organization-specific questions were also asked in addition to the initial questions that were mainly derived from the TOE framework and the Institutional Theory. To remove the different types of biases such as intrinsic and methodological, and to maintain the validity of the research, the following measures were taken:

- Every activity involved in the data collection was properly documented.

- In addition to the interviews, secondary data were collected by reviewing existing literature on BCT, white papers, Australian government reports, and organizations' websites to get further insights into the phenomenon and to corroborate the findings. Some documents were provided by the interviewees.

- Interviewees were selected from diverse business functions and IT backgrounds.

- Instead of structuring the interviews around the TOE framework and the Institutional Theory, the interviewees were encouraged to mention those factors that they thought were important while deciding BCT adoption in their organizations.

- The interviewees were free to ask any questions about the research.

- The interviews were administered by a team of two persons, i.e. authors of this paper, who had extensive knowledge of BCT, as suggested by Eisenhardt [51]. One team member handled the interview questions, while the other recorded the interview and took notes.

- At the end of the interview, the interviewees were asked to verify the summary of the major findings. Later, they were provided a transcribed copy of the interview.

Every interview was audio recorded with the written/verbal consent of the interviewee. To maintain confidentiality, the interviewees were assured that their names would be replaced with pseudonyms.

\section{Interview Data Analysis and Findings}

To analyse the interview data, the study followed the guidelines of Corbin and Strauss [52] using QSR NVivo software. The data were analyzed in multiple iterations. The steps involved in the analysis are given below.

Examination. All the transcribed interviews were thoroughly examined, line-by-line.

Open Coding. Underlying concepts were identified. 
Axial Coding. The identified concepts were grouped, based on their similarities and differences, into categories.

Mapping. The categories were mapped with the corresponding contexts of the TOE framework as shown in Figure 1.

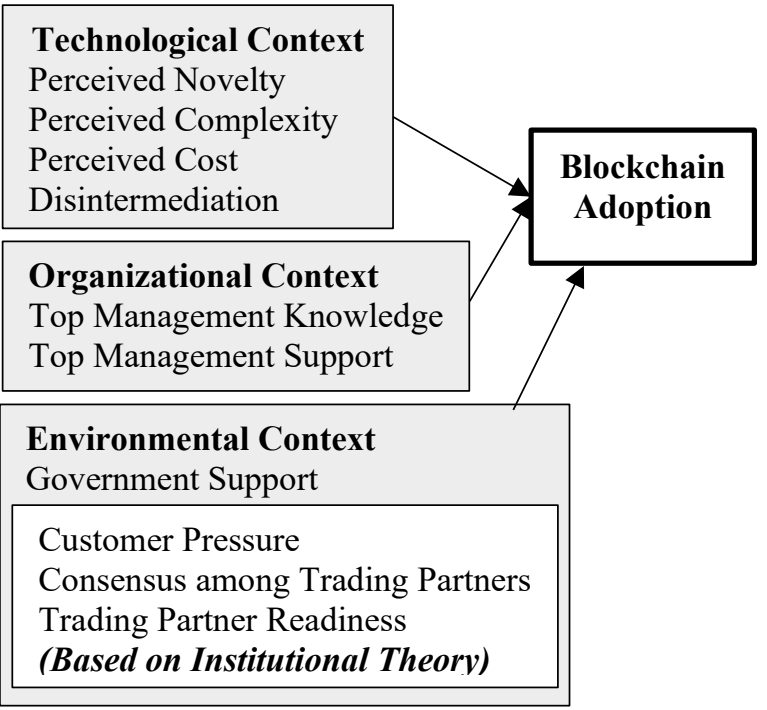

Figure 1. Factors influencing BCT adoption

Table 2 shows a frequency analysis of responses of the informants for every factor, adapted from [53].

Table 2. Frequency analysis of the response

\begin{tabular}{|c|c|c|c|}
\hline \multirow[b]{2}{*}{ Factors } & \multicolumn{3}{|c|}{$\begin{array}{c}\text { Frequency of } \\
\text { Responses }\end{array}$} \\
\hline & 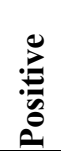 & 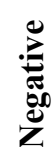 & $\begin{array}{l}\stackrel{0}{\Xi} \\
\stackrel{\mathscr{B}}{0} \\
\stackrel{0}{Z}\end{array}$ \\
\hline Perceived Novelty & 15 & 6 & 2 \\
\hline Perceived Complexity & 0 & 20 & 3 \\
\hline Perceived Cost & 0 & 19 & 4 \\
\hline Disintermediation & 11 & 10 & 2 \\
\hline Top Management Knowledge & 18 & 0 & 5 \\
\hline Top Management Support & 23 & 0 & 0 \\
\hline Government Support & 10 & 12 & 1 \\
\hline Customer Pressure & 14 & 0 & 9 \\
\hline $\begin{array}{l}\text { Consensus among Trading } \\
\text { Partners }\end{array}$ & 5 & 15 & 3 \\
\hline Trading Partner Readiness & 4 & 18 & 1 \\
\hline
\end{tabular}

The following sub-sections explain the findings of this study in the contexts of the TOE framework.

\subsection{Technological Context}

This section reports the influence of BCT characteristics on its adoption.

Perceived BCT Novelty. The perceived novelty of BCT refers to the beliefs about its newness or freshness in the eyes of its potential adopters. Rogers [40] and Wells et al. [54] reported novelty as a fundamental characteristic that determines an organization's reaction to the adoption of new technology. Most of the informants commented that the novelty of BCT was an important factor while deciding the adoption of $\mathrm{BCT}$ in their organizations.

"The main motivation for me to adopt BCT is its newness. I think blockchain and its applications like Bitcoin will become day-to-day usage in the future. So for me, I saw it as an opportunity to get in while the industry is still developing on an early level and being able to participate in it." said the CEO of a crypto exchange (A11).

Some respondents reported perceived novelty as a demotivating factor for BCT adoption due to its limited number of trials in the market, and its benefits are not widely observable.

Perceived Complexity. Perceived complexity is the degree to which organizations perceive an innovation to be relatively difficult to understand and use [40]. There was consensus among the informants that BCT is a complex technology that hinders an organization from its adoption. One of the informants said:

"The other thing that is causing slow adoption of $B C T$ among Australian organization is probably people are used to GUIs of the existing data structures and data warehouses, and these are well-developed and people understand how to use those GUIs, whereas, with the BCT at the moment, has not been done a lot of development to make it easy for users to use it as a data structure and database type of solution" (A7)

Perceived Cost: The informants were consistently agreed that the perceived cost inhibits the organizational adoption of BCT. One of them stated (A13):

"Adoption of BCT involves a significant switching cost of changing fundamentally how a business is interacting with its stakeholders and customers and suppliers. There is substantial integration cost that demotivates organizations to adopt BCT".

BCT Disintermediation. BCT enables peer-peer data transfer without the need of any third party over a decentralized network [1]. Most of the informants considered disintermediation as a motivational factor. As said by one of them (A12):

"We adopted BCT because it provides the freedom to our customers to make a payment without any bank. 
Now we have customers beyond the borders. If you are paying from countries like where there is like very little banking infrastructure, BCT makes it possible and easier to pay for anything."

The disintermediation was not a source of motivation for every informant to adopt BCT. For some, this was a threat to their business. As stated by one of them (A18):

"As the BCT removes the intermediaries, so the organizations such as banks, distributors, brokers that are doing their business as middleman do feel insecure to adopt it. Adoption of BCT has no meaning to them because they are earning money because of working as an intermediary. If $B C T$ removes them, this makes no sense for them to be part of this technology."

\subsection{Organizational Context}

In this sub-section, we include the factors that are internally related to organizations and influence their decision to adopt BCT.

Top Management Knowledge. The decision to adopt new technology is influenced by the knowledge, which an organization acquired about that technology to remove its uncertainties. Since top management e.g. $\mathrm{CEO}$ are the main decision-makers in an organization, therefore, their knowledge about new technology determines the attitude towards its adoption [55]. The informants were agreed that the majority of the recent top management at different organizations do not have sufficient knowledge about BCT and thus they feel reluctant about its adoption. One of them commented (A14):

"So basically, there is a need for the top management to acquire BCT knowledge. It is a prerequisite for its adoption. Currently, top management does not have a good understanding of how the BCT is going to give value to their businesses. Low BCT knowledge is causing uncertainties and doubts about its adoption."

Top Management Support. The informants were agreed that without the recognition and support of the top leadership, adoption of BCT was not possible within an organization. "we adopted BCT because our top management was supportive for it.", said a CTO of an organization (A10). The clear strategic direction and enthusiasm of the top management were reported influential on BCT adoption. A project manager explained it by saying (A5):

"Our CEO acknowledged that the adoption of BCT would bring an increase in the gross profit of our company. Our leadership was very certain about the benefits of BCT" He further added, "Successful adoption of BCT in our company was not possible without the support of our leadership."

\subsection{Environmental Context}

This sub-section includes the factors, external to an organization, which were reported influential on the organizational adoption of BCT.

Government Support. Government support and regulations drafted for new technology play an important role in its adoption [56]. Informants showed a mixed response about the government support and the regulations formulated for BCT. A formerly senior computer forensic officer of a government department said (A15):

"I think that for blockchain as a technology, the Australian government is quite supportive of in some aspects when it is going to lead to greater transparency and potentially better border processes and things like blockchain as a data warehousing, data architecture solution. I think where the regulations are pertinent to the cryptocurrency or finance-related matters; it is obviously where I see a lack of regulations by the Australian government at the moment, which may be causing uncertainty about the BCT and its adoption"

Customer Pressure. Customers are considered an important part of an organization's environment. They have the power to influence an organization's decision to initiate and implement certain business practices [57]. Customer pressure played a pivotal role in the adoption of BCT, reported by many informants. They mentioned that customer-oriented organizations adopt BCT because of their customer demands and needs. A solution architect opined on this by saying (A19):

"There are many customers who have the requirement of data provenance, which we think can be achieved through the BCT",

It was further supplemented by the CEO of an organization (A20):

"BCT is kind of considering the customer's future needs. We provide technology solutions to businesses. So, for us, the key incentive to adopt BCT is if our customers are coming asking for that"

Consensus among Trading Partners. Since the $\mathrm{BCT}$ is a network technology that is maintained by the participating organizations. Therefore, mutual consensus on common terms and conditions among the trading partners was reported very important to adopt BCT. The informants pointed out that the need for consensus among trading partners as a potential barrier to BCT adoption. One of them said (A23):

"BCT adoption requires all the organizations over the network to reach a single mutual consensus over the validation of transaction, monitoring of all records and 
validating or certifying the possession of assets digitally, and confirmation of the settlements. Organizations struggle to agree upon common terms and conditions to participate in the BCT network. Due to be an interorganizational system, the interdependencies, power of the BCT initiator, and trust toward the organizations become critical issues that impede to reach a mutual consensus among the organizations."

Trading Partner Readiness. The informants stated that the adoption of BCT requires the readiness of all trading partners, which is measured in terms of their IT sophistication and financial resources [58]. The respondents were agreed that the decision to adopt BCT depends on the willingness and ability of potential partners. One of them stated (A2):

"Since the BCT is a cross-organization technology, you can get its value when all the organizations are ready to adopt it. If an organization is motivated and ready to adopt BCT but its partner organizations are unready due to not having sufficient technical skills or finance would be unable to adapt."

\section{Discussion and Contributions}

Our study finds that the adoption of BCT among Australian organization is influenced by the TOE framework and Institutional Theory factors. The TOE factors include perceived novelty, complexity, cost, disintermediation, top management knowledge and support, and government support whereas the Institutional Theory factors comprise customer pressure, trading partner readiness, and consensus among trading partners. The findings indicate that despite the positive influence of the factors derived from the TOE framework, the organizations still cannot decide BCT adoption alone unless they consider the Institutional Theory factors. The findings not only confirm the impact of the factors i.e. complexity, cost, top management support and knowledge, and government support that reported in the existing studies on BCT adoption [6, 22-25, 59], but they also introduce some new factors such as novelty and disintermediation of BCT, consensus among trading partners, trading partners readiness, which were not reported in the earlier literature to best of our knowledge.

The perceived novelty has been found as an enabler and an inhibitor in BCT adoption. There is a need to minimize the negative impact of BCT novelty. We suggest that adopter organizations should demonstrate the benefits that BCT brought into their business. If BCT has more trials and observability in the market, there will be fewer adverse effects of BCT novelty on its adoption [40].
Perceived complexity is found as a negative factor in BCT adoption. This finding is in line with Wong, et al. [6]. He discovered that the adoption of BCT lowers if organizations perceive the use of BCT is complex. Complexity to integrate BCT with the existing IT infrastructure, consensus algorithms, cryptography, and data storage redundancy impediment BCT adoption. Therefore, the organizations preparing to adopt BCT must properly address these issues, failing which may cause serious problems of undesirable outcomes of this technology.

Perceived cost is found to be a hindering factor for BCT adoption. Kulkarni and Patil [22] also stated perceived cost as an inhibitor for the adoption of BCT in India. We suggest that organizations should carefully analyze the cost involved in BCT before deciding its adoption. Nevertheless, the use of BCT is considered a cost-effective solution in terms of funds transfer [26], however, the costs involved in its adoption, for instance, change of internal systems, hiring of highly paid technical staff, energy consumption, and installation of additional hardware to store data that organizations should accurately estimate to avoid any future losses and unwanted consequences [6].

Disintermediation is one of the main features of BCT that is considered a breakthrough in today's digital business world [60]. Our findings report some negative impacts of disintermediation on organizations, which are working as intermediaries, to adopt BCT. They are not convinced to adopt BCT because of the disintermediation feature of BCT. This insight intrigues BCT developers, proponents, and practitioners to find ways to make BCT usable for intermediary organizations.

Our findings show that BCT adoption is significantly dependant on the discretion of the organization's management because they are the persons who have the final say to adopt or do not adopt a technology [59]. The top management provides funds and takes risks to adopt BCT. However, if the top management lack BCT knowledge, there are fewer chances that an organization would go for BCT adoption. The handling of probable change that BCT causes and the employees' acceptance towards BCT are not possible without the active and positive involvement of top management. Therefore, it is important to obtain the support of top management for the successful adoption of BCT within an organization.

Australian government support is seen as essential to BCT adoption. Organizations especially those providing financial services are actively seeking the government to develop more clear policies and legal frameworks to enhance their trust in BCT. The findings demonstrate that the legal uncertainties in handling 
privacy in BCT are depicting barriers towards BCT adoption. This finding is consistent with Kühn, et al. [24] that reported the similar effects of government support on BCT adoption in Germany. It urges the Australian government to develop more clear guidelines and support for the adoption of BCT.

Most of the extant studies explore the BCT adoption from a standalone technology perspective and ignore its inter-organizational aspect, which requires the involvement of the trading partners and customers. Our findings provide new valuable insight on the influence of the trading partners on BCT adoption. The consensus among trading partners and their readiness are found to be salient factors for the successful adoption of BCT. Therefore, organizations need to know that BCT is like an inter-organizational system [27] and it has different requirements and protocols for its adoption as compared to the standalone technologies like ERP, RFID, etc.

The following sections explain the theoretical and practical contributions of the study.

\subsection{Theoretical Contribution}

Our study contributes to the existing body of knowledge in the following ways: (1) preliminarily identifies the factors influencing Australian organizations to adopt BCT, (2) discovers new factors: BCT novelty and disintermediation, and consensus among trading partners in Australian perspective that were not considered in previous IT adoption research in general, and BCT adoption in particular, (3) integrates the TOE framework and the Institutional Theory, which were not combined by any of the past studies on BCT adoption, and (4) validates the impact of different factors, mentioned in the prior studies on BCT adoption, for example, top management support, government support, cost, and complexity $[6,25,26]$.

\subsection{Practical Contribution}

The practical relevance of this study is that its findings would help: (1) BCT consultants and service providers to better understand the influence of different factors on BCT adoption in Australia and consequently formulate better strategies and informed decisions, (2) managers and decision-makers to carefully evaluate the BCT complexity and cost concerns as well as the other factors before deciding the adoption of BCT in their organizations, (3) service providers in deciding to expand their BCT related services into other countries having characteristics similar to Australia e.g. New Zealand, (4) Australian government and private organizations like Blockchain Australia to address the major issues in the adoption of BCT and develop policies and actions to remove uncertainties of potential BCT-adopter organizations.

Further, the findings reflect the importance of top management knowledge in the adoption of BCT. Therefore, the organizations could equip their staff with the knowledge and skills necessary for BCT adoption. The study reports the shortage of BCT related technical skills in Australia. The educational institutions could take this finding as a business opportunity to plan and develop suitable BCT training programs and courses.

\section{Conclusion}

The study investigates the factors influencing organizational adoption of BCT in Australia by applying an interpretive qualitative research approach; using the integrated theoretical lens of the TOE framework and the Institutional Theory. The data was collected through semi-structured interviews.

The findings of the study show that the organizational adoption of BCT is influenced by the factors related to the technological context (novelty, complexity, cost, and disintermediation of BCT), organizational context (top management knowledge and support), and environmental context (government support, customer pressure, consensus among trading partners, and trading partner readiness) of the TOE framework. The study provides both theoretical and practical contributions.

The scope of the study is limited to cover BCT adoption from the Australian perspective only. Therefore, the external validity of the findings cannot be assured. Extension of the current work will expand it further to generalize the findings through a quantitative study. Future work can also focus on investigating BCT adoption by considering public, private, and consortium BCT separately in Australia.

\section{References}

[1] S. Nakamoto, "Bitcoin: A peer-to-peer electronic cash system," Manubot, 2019.

[2] M. Friedlmaier, A. Tumasjan, and I. M. Welpe, "Disrupting industries with blockchain: The industry, venture capital funding, and regional distribution of blockchain ventures," in Venture Capital Funding, and Regional Distribution of Blockchain Ventures (September 22, 2017). Proceedings of the 51st Annual Hawaii International Conference on System Sciences (HICSS), 2018.

[3] W. G. Research, "Blockchain Market Shares, Market Strategies, and Market Forecasts, 2018 to 2024," 14/04/2019 2018. [Online]. Available: https://www.ibm.com/downloads/cas/PPRR983X 
[4] W. E. Forum, "Building Value with Blockchain Technology," 2019. [Online]. Available: http://www3.weforum.org/docs/WEF_Building_Value with Blockchain.pdf

[5] B. Council. "Top 10 Companies that already adopted Blockchain." $\quad$ https://www.blockchaincouncil.org/blockchain/top-10-companies-that-havealready-adopted-blockchain/ (accessed 20-01-2019, 2019).

[6] L.-W. Wong, L.-Y. Leong, J.-J. Hew, G. W.-H. Tan, and K.-B. Ooi, "Time to seize the digital evolution: Adoption of blockchain in operations and supply chain management among Malaysian SMEs," International Journal of Information Management, p. 101997, 2019.

[7] Deloitte, "Deloitte's 2018 global blockchain survey," 2018. Accessed: 27/07/2019. [Online]. Available: https://www2.deloitte.com/content/dam/Deloitte/cz/Do cuments/financial-services/cz-2018-deloitte-globalblockchain-survey.pdf

[8] PWC, "PwC's Global Blockchain Survey 2018," 2018. Accessed: 27/07/2019. [Online]. Available: http://explore.pwc.com/blockchain/Execsummary?WT.mc id=CT11-PL1000-DM2-TR1-LS4ND30-TTA5-CN US-GX-xLoSBlockchain-LBPwCExecSum\&eq =CT11-PL1000-DM2-CN_US-GXxLoSBlockchain-LB-PwCExecSum

[9] J. M. Woodside, F. K. Augustine Jr, and W. Giberson, "Blockchain technology adoption status and strategies," Journal of International Technology and Information Management, vol. 26, no. 2, pp. 65-93, 2017.

[10] CA, "The Future of Blockchain," 2017. [Online]. Available: https://www.charteredaccountantsanz.com//media/c1430d6febb3444192436ffc8b685c7c.ashx

[11] M. Streng, "Blockchain-the Case for Market Adoption of the Distributed Ledger," in Digital Marketplaces Unleashed: Springer, 2018, pp. 65-70.

[12] P. T. Duy, D. T. T. Hien, D. H. Hien, and V.-H. Pham, "A survey on opportunities and challenges of Blockchain technology adoption for revolutionary innovation," in Proceedings of the Ninth International Symposium on Information and Communication Technology, 2018, pp. 200-207.

[13] F. Parino, M. G. Beiró, and L. Gauvin, "Analysis of the bitcoin blockchain: Socio-economic factors behind the adoption," EPJ Data Science, vol. 7, no. 1, p. 38, 2018.

[14] F. R. Batubara, J. Ubacht, and M. Janssen, "Challenges of blockchain technology adoption for e-government: a systematic literature review," in Proceedings of the 19th Annual International Conference on Digital Government Research: Governance in the Data Age, 2018: ACM, p. 76.

[15] J. Kokina, R. Mancha, and D. Pachamanova, "Blockchain: Emergent industry adoption and implications for accounting," Journal of Emerging Technologies in Accounting, vol. 14, no. 2, pp. 91-100, 2017.

[16] R. Taufiq, A. N. Hidayanto, and H. Prabowo, "The Affecting Factors of Blockchain Technology Adoption of Payments Systems in Indonesia Banking Industry," in 2018 International Conference on Information
Management and Technology (ICIMTech), 2018: IEEE, pp. 1-9.

[17] H. Wang, K. Chen, and D. Xu, "A maturity model for blockchain adoption," Financial Innovation, vol. 2, no. 1, p. 12, 2016.

[18] S. Kamble, A. Gunasekaran, and H. Arha, "Understanding the Blockchain technology adoption in supply chains-Indian context," International Journal of Production Research, pp. 1-25, 2018.

[19] S. Supranee and S. Rotchanakitumnuai, "The Acceptance of the Application of Blockchain Technology in the Supply Chain Process of the Thai Automotive Industry," ed: ICEB, 2017.

[20] N. Kshetri and E. Loukoianova, "Blockchain adoption in supply chain networks in Asia," IT Professional, vol. 21, no. 1, pp. 11-15, 2019.

[21] F. Holotiuk and J. Moormann, "Organizational adoption of digital innovation: The case of blockchain technology," 2018.

[22] M. Kulkarni and K. Patil, "Block Chain Technology Adoption for Banking Services-Model based on Technology-Organization-Environment theory," Available at SSRN 3563101, 2020.

[23] F. Koster and H. Borgman, "New Kid On The Block! Understanding Blockchain Adoption in the Public Sector," in Proceedings of the 53rd Hawaii International Conference on System Sciences, 2020.

[24] O. Kühn, A. Jacob, and M. Schüller, "Blockchain adoption at German logistics service providers," in Artificial Intelligence and Digital Transformation in Supply Chain Management: Innovative Approaches for Supply Chains. Proceedings of the Hamburg International Conference of Logistics (HICL), Vol. 27, 2019: Berlin: epubli GmbH, pp. 387-411.

[25] T. Clohessy and T. Acton, "Investigating the influence of organizational factors on blockchain adoption," Industrial Management \& Data Systems, 2019.

[26] S. Albrecht, S. Reichert, J. Schmid, J. Strüker, D. Neumann, and G. Fridgen, "Dynamics of blockchain implementation-a case study from the energy sector," in Proceedings of the 51st Hawaii International Conference on System Sciences, 2018.

[27] F. Werner, M. Basalla, J. Schneider, D. Hayes, and J. Vom Brocke, "Blockchain Adoption from an Interorganizational Systems Perspective-A MixedMethods Approach," Information Systems Management, pp. 1-16, 2020.

[28] S. Australia, "Roadmap for blockchain standards," 2016. [Online]. Available: https://www.standards.org.au/getmedia/ad5d74db8da9-4685-b17190142ee0a2e1/Roadmap for Blockchain Standards re port.pdf.aspx

[29] DISER, "The National Blockchain Roadmap," 2020 2020. [Online]. Available: https://www.industry.gov.au/sites/default/files/202002/national-blockchain-roadmap.pdf

[30] CRCNA. "Australian government in Water Ledger blockchain for trading water rights." https://crcna.com.au/research/projects/improving- 
water-markets-and-trading-through-new-digitaltechnologies (accessed 2020).

[31] DFAT, "Advancing Australia's blockchain industry," ed, 2018.

[32] (2018). Australian Blockchain Mission to Consensus 2018. [Online] Available: https://www.austrade.gov.au/events/events/aublockchain-mission-to-consensus-ny

[33] NAB. "Embracing innovation puts the ASX at the forefront of new technology." https://business.nab.com.au/embracing-innovationputs-the-asx-at-the-forefront-of-new-technology38408/ (accessed.

[34] IBM, "Australian Federal Government signs a \$1B fiveyear agreement with IBM," ed, 2018.

[35] B. Australia. "Promoting blockchain innovation in Australia." https://blockchainaustralia.org/ (accessed 2020).

[36] Australia, "Opportunities and implications of blockchain in Australia," 2016. [Online]. Available: https://www2.deloitte.com/content/dam/Deloitte/au/Do cuments/financial-services/deloitte-au-fs-opportunitiesimplications-blockchain-australia-180516.pdf

[37] E. I. Unit, "Preparing for disruption Technological Readiness Ranking," pp. 1-21, 2018. [Online]. Available: $\quad$ http://pages.eiu.com/rs/753-RIQ438/images/Technological_readiness_report.pdf.

[38] ACS, "Blockchain 2030, A Look at the Future of Blockchain in Australia," Australian Computing Society, 2019. Accessed: 14/04/2019. [Online]. Available: https://www.acs.org.au/content/dam/acs/acspublications/ACS-Data61-Blockchain-2030-Report.pdf

[39] T. Oliveira and M. F. Martins, "Literature review of information technology adoption models at firm level," Electronic Journal of Information Systems Evaluation, vol. 14, no. 1, p. 110, 2011.

[40] E. M. Rogers, Diffusion of innovations. Simon and Schuster, 2003.

[41] L. Tornatsky and M. Fleischer, "The process of technology innovation," Lexington, MA, Lexington Books, 1990

[42] J. Baker, "The technology-organization-environment framework," in Information systems theory: Springer, 2012, pp. 231-245.

[43] S. Verma and S. S. Bhattacharyya, "Perceived strategic value-based adoption of Big Data Analytics in emerging economy," Journal of Enterprise Information Management, 2017.

[44] I. Troshani, C. Jerram, and M. Gerrard, "Exploring the organizational adoption of Human Resources Information Systems (HRIS) in the Australian public sector," 2010

[45] P. J. DiMaggio and W. W. Powell, "The iron cage revisited: Institutional isomorphism and collective rationality in organizational fields," American sociological review, pp. 147-160, 1983.

[46] H. K. Klein and M. D. Myers, "A set of principles for conducting and evaluating interpretive field studies in information systems," MIS quarterly, pp. 67-93, 1999.
[47] R. K. Yin, Case study research and applications. Design and methods. Sage publications, 2017.

[48] C. E. Hill, B. J. Thompson, and E. N. Williams, "A guide to conducting consensual qualitative research," The counseling psychologist, vol. 25, no. 4, pp. 517-572, 1997.

[49] B. G. Glaser and A. L. Strauss, Discovery of grounded theory: Strategies for qualitative research. Routledge, 2017.

[50] A. Bryman, Social research methods. Oxford university press, 2016.

[51] K. M. Eisenhardt, "Building theories from case study research," Academy of management review, vol. 14, no. 4, pp. 532-550, 1989.

[52] J. Corbin and A. Strauss, Basics of qualitative research: Techniques and procedures for developing grounded theory. Sage publications, 2014.

[53] O. M. S. H. Ali, "The perceived benefits of cloud computing technology for regional municipal governments and barriers to adoption," University of Southern Queensland, 2016.

[54] J. D. Wells, D. E. Campbell, J. S. Valacich, and M. Featherman, "The effect of perceived novelty on the adoption of information technology innovations: a risk/reward perspective," Decision Sciences, vol. 41, no. 4, pp. 813-843, 2010.

[55] J. Y. Thong, "An integrated model of information systems adoption in small businesses," Journal of management information systems, vol. 15, no. 4, pp. 187-214, 1999.

[56] D. Cetindamar, "The role of regulations in the diffusion of environment technologies: micro and macro issues," European Journal of Innovation Management, 2001.

[57] F. Wu and Y.-K. Lee, "Determinants of ecommunication adoption: the internal push versus external pull factors," Marketing Theory, vol. 5, no. 1, pp. 7-31, 2005.

[58] K. Zhu, S. Dong, S. X. Xu, and K. L. Kraemer, "Innovation diffusion in global contexts: determinants of post-adoption digital transformation of European companies," European journal of information systems, vol. 15, no. 6, pp. 601-616, 2006.

[59] B. W. Barnes III and B. Xiao, "Organizational Adoption of Blockchain Technology: An Ecosystem Perspective," Technology, vol. 12, pp. 15-2019, 2019.

[60] G. J. Larios-Hernández, "Blockchain entrepreneurship opportunity in the practices of the unbanked," Business Horizons, vol. 60, no. 6, pp. 865-874, 2017.

\section{Acknowledgement}

We thank Dr. Anitra Goriss-Hunter, Federation University Australia, for her suggestions, language editing and proofreading of this paper. 